\title{
A pilot study to examine the effect of pea protein on limiting the loss of muscle mass during weight loss: Study design and rationale
}

\author{
Jaime L. Clark ${ }^{1,2}$, Carla G. Taylor ${ }^{1-3}$, Laetitia Guérin-Deremaux ${ }^{4}$, Catherine Lefranc-Millot ${ }^{5}$ and Peter Zahradka ${ }^{1-3 *}$ \\ ${ }^{1}$ Department of Physiology and Pathophysiology, Rady Faculty of Health Sciences, University of Manitoba, Winnipeg, MB, R3E 0T5, Canada \\ ${ }^{2}$ Canadian Centre for Agri-Food Research in Health and Medicine, St. Boniface Hospital Albrechtsen Research Centre, Winnipeg, MB, R2H 2A6, Canada \\ ${ }^{3}$ Department of Food and Human Nutritional Sciences, Faculty of Agricultural and Food Sciences, University of Manitoba, Winnipeg, MB, R3T 2N2, Canada \\ ${ }^{4}$ Roquette Frères, Nutrition and Health R\&D, 62080 Lestrem, France \\ ${ }^{5}$ Roquette Frères, Nutriton and Health R\&D, 59110 La Madeleine, France
}

\begin{abstract}
Objectives: Weight loss has physiological benefits for people with obesity; however, the accompanying loss of muscle mass may pose additional health risks. High protein diets are effective for retaining muscle mass during weight loss, but it has yet to be determined if all protein sources are beneficial. This paper describes the design and rationale of a randomized, double-blinded, comparator-controlled single-site clinical trial to investigate the effects of pea protein, whey protein, or maltodextrin supplementation on muscle mass and functionality in males and females with obesity undertaking a weight loss regimen.

Methods: Sixty obese participants will be randomized to consume pea protein, whey protein, or maltodextrin for 12 weeks as part of a calorie-restricted diet. The primary endpoints are changes in muscle mass and functionality as measured by dual-energy x-ray absorptiometry and physical performance tests (hand grip strength, gait speed), respectively. Secondary endpoints include changes in body weight and composition, resting energy expenditure and measures of inflammation, metabolic and cardiovascular function, as well as $24 \mathrm{~h}$ activity patterns and food intake over time.

Conclusion: This trial will provide novel and important findings on how these different protein sources affect the loss of muscle mass expected to occur during weight loss. Furthermore, this research may support the utility of pea protein as a functional plant-based ingredient for promoting favourable changes in body composition during weight loss. The study is registered on Clinicaltrials.gov (NCT04123938).
\end{abstract}

\section{Introduction}

Obesity is a severe global health crisis characterized by excess or abnormal body fat accumulation that can dramatically impair health. Globally, over 650 million adults were considered obese in 2016 [1], and the rates continue to rise such that it is projected that $20 \%$ of the world's population will be obese in the next decade [2]. In Canada, one in four adults currently live with excess weight obesitycanada.ca/ understanding-obesity [3], while in the United States the prevalence of obesity is nearly half the population (42.4\% in 2017-2018) [4].

The need to intervene in the global obesity epidemic stems largely from the risk of developing nearly every chronic morbidity, from conditions such as dyslipidaemia to diseases such as depression, type 2 diabetes, osteoarthritis, cardiovascular disease, and certain cancers, to name a few [2]. Furthermore, there is unequivocal evidence that overweight and obesity increase the risk for total mortality [2].

Weight loss can decrease health risk factors and improve longevity and quality of life for people with obesity $[2,5,6]$. Diet and physical activity play prominent roles in weight maintenance, and diet-induced weight loss can reduce or resolve metabolic risk factors such as insulin resistance, high blood pressure, and dyslipidemia. However, the loss of body weight includes both fat and lean tissue (including muscle) mass, the latter of which may have some negative consequences. Loss of muscle mass can affect physical strength, performance, and metabolic regulation [7], as well as increase the risk of sarcopenia (the age-related loss of muscle mass and decline in muscle strength) and other chronic diseases $[7,8]$.

Several strategies have been studied for preserving muscle mass during weight loss. One of the most effective methods for people with obesity is increased consumption of protein [5,9]. Whey protein is currently the highest quality and most preferred protein supplement to support muscle growth; reportedly, whey protein either out-performs $[7,10]$ or performs equally $[11,12]$ to other protein sources prepared either from animals (e.g. casein) or plants (e.g. soybean). Recently, health authorities have recommended an increase in plant-based protein intake over animal protein consumption $[11,13,14]$. Thus, pea protein is receiving more interest as an alternative protein source due to its high nutritional and functional values [15], lower greenhouse gas emissions compared to animal proteins [16], and very low allergenic potential, all of which make pea protein more acceptable for dietary intervention than other common protein sources such as milk (casein and whey),

*Correspondence to: Peter Zahradka, Department of Physiology and Pathophysiology, Rady Faculty of Health Sciences, University of Manitoba, Winnipeg, MB, R3E 0T5, Canada, Tel: 1-204-237-3501; E-mail: pzahradka@ sbrc.ca

Key words: pea protein, whey protein, obesity, muscle mass, muscle function, weight loss

Received: August 20, 2021; Accepted: August 27, 2021; Published: August 31, 2021 
Table 1. Inclusion and exclusion criteria

\begin{tabular}{|c|c|}
\hline Inclusion criteria & $\begin{array}{l}\text { 1) Male or female aged } 30 \text { to } 50 \text { years. Females must not be pregnant or lactating and must be using a highly effective method for avoidance of } \\
\text { pregnancy. } \\
\text { 2) Body mass index } \geq 30 \text { and body weight does not exceed } 350 \mathrm{lbs} \text {. } \\
\text { 3) Fat mass } \geq 23 \% \text { for males and } \geq 32 \% \text { for females. } \\
\text { 4) Participants must be willing to maintain a stable level of physical activity during participation in the study. } \\
\text { 5) With the following blood parameters: } \\
\text { (a) plasma creatinine } \leq 265 \mu \mathrm{mol} / \mathrm{L} \text {; } \\
\text { (b) LDL-cholesterol }<5 \mathrm{mmol} / \mathrm{L} \text {; } \\
\text { (c) aspartate aminotransferase }<160 \mathrm{U} / \mathrm{L} \text {, alanine aminotransferase }<150 \mathrm{U} / \mathrm{L} \text {; } \\
\text { (d) glycated hemoglobin }<6.5 \% \text {. } \\
\text { 6) Systolic and diastolic blood pressure levels }<160 \mathrm{mmHg} \text { and }<100 \mathrm{mmHg} \text {, respectively. } \\
\text { 7) Participants must be on a stable regime if taking vitamin and mineral/dietary/herbal supplements for one month prior to study onset and while } \\
\text { participating in the study. } \\
\text { 8) Participants must not be taking protein supplements for one month prior to study onset and be willing to continue doing so for the duration of } \\
\text { the study. } \\
\text { 9) Participants must have not donated blood or blood products (e.g. platelets) during the past two months and agree not to do so while participating } \\
\text { in the study. } \\
\text { 10) Participants must not have participated in another dietary intervention trial for the past month and must agree to not start another dietary } \\
\text { intervention trial or weight loss program for the duration of this study; they must be willing to comply with the protocol requirements and } \\
\text { procedures. } \\
\text { 11) Participants must be willing to provide informed consent. }\end{array}$ \\
\hline Exclusion criteria & $\begin{array}{l}\text { Participants meeting any of the following criteria must not be enrolled in the study: } \\
\text { 1) Experienced a cardiovascular event (e.g. heart attack, stroke) or had a surgical procedure for cardiovascular disease (e.g. bypass, stent), } \\
\text { presence of diabetes, chronic renal disease, liver disease (with exception of fatty liver), rheumatoid arthritis, immune disorder or disease (e.g. } \\
\text { multiple sclerosis, leukemia), cancer in the previous five years, neurological disorders, gastrointestinal disorders or gastrointestinal surgery or } \\
\text { bariatric surgery, or liposuction. } \\
\text { 2) Taking medications for blood glucose management. } \\
\text { 3) Taking medications or natural health products/supplements associated with weight gain or weight loss (e.g. prednisone, certain cold } \\
\text { medications). } \\
\text { 4) Body weight has not been stable ( } \pm 5 \% \text { ) over the past three months. } \\
\text { 5) Medical history of gastrointestinal reactions or allergies to peas, pea protein, whey protein or maltodextrin, or to one or more ingredients in } \\
\text { the beverages and foods that will be provided which significantly limits the number of items that can be used for delivery of the protein powders } \\
\text { or maltodextrin. } \\
\text { 6) Current (within the past } 30 \text { days) bacterial, viral or fungal infection. } \\
\text { 7) Uncontrolled hypothyroidism. } \\
\text { 8) Uncontrolled blood pressure. } \\
\text { 9) Bleeding disorders. } \\
\text { 10) Any acute medical condition or surgical intervention within the past three months. } \\
\text { 11) Cigarette/cigar smoking or use of tobacco products within the last } 12 \text { months or during participation in the study. } \\
\text { 12) Consumption of }>10 \text { alcoholic beverages per week or }>2 \text { alcoholic beverages per day within the last } 3 \text { months or while participating in the } \\
\text { study. } \\
\text { 13) Drug and/or alcohol abuse. } \\
\text { 14) Psychological disorder(s). } \\
\text { 15) Unable to obtain blood sample at the screening or baseline visit. }\end{array}$ \\
\hline
\end{tabular}

soy, or wheat [17]. Indeed, pea protein is a major component of the various meat-alternative formulations gaining public attention $[18,19]$.

To date, no one has examined the effect of pea protein on preserving muscle mass during weight loss in an obese population, and thus it is not known how it will perform compared to whey protein. This paper describes the design and rationale of a double-blinded, randomized, placebo-controlled clinical trial to examine whether 12 weeks of pea protein or whey protein intervention can prevent loss of muscle mass and functionality in obese individuals undertaking a weight loss regimen. We are testing the hypothesis that pea protein is equivalent to whey protein in preventing loss of muscle mass and functionality under conditions of weight loss.

\section{Methods and analysis}

\section{Study design and population}

This study will be a single-site, double-blinded, randomized, comparator-controlled dietary intervention trial conducted at the $\mathrm{IH}$ Asper Clinical Research Institute, St Boniface Hospital, Winnipeg, Canada. Eligible participants will be randomly assigned to receive pea protein, whey protein, or maltodextrin (non-protein comparator) for 12 weeks. Participants will be on-site for assessments at screening, prestudy visit, dietitian visit, week 0 , week 6 , and week 12 . The full list of inclusion and exclusion criteria is shown in Table 1.
The primary outcomes of this study are changes in muscle mass (lean body mass) and muscle function (hand grip strength and gait speed test).

The secondary outcomes of this study include changes in fat mass, body weight and body mass index (BMI), calf and thigh circumferences, arm circumference, waist circumference, waist-to-height ratio, resting energy expenditure, C-reactive protein, Homeostatic Model Assessment for Insulin Resistance (HOMA-IR), glycated hemoglobin, blood lipid profile (total cholesterol, LDL-cholesterol, HDL-cholesterol, triglycerides), kidney function (urinary albumin, creatinine, urea; blood urea nitrogen, serum creatinine), liver function (alanine aminotransferase (ALT) and aspartate aminotransferase (AST)), systolic and diastolic blood pressure, and blood vessel function. Additional secondary outcomes include changes over time of activity patterns obtained by activity trackers, appetite, eating habits, health and wellbeing information obtained from study questionnaires, nutrient intake determined by 3-day food records, and preferences incorporating protein powders into foods and beverages from the food logs.

\section{Randomization and blinding}

Unique randomization codes will be generated by an un-blinded statistician not affiliated with the research team. The codes will ensure that participants are randomly assigned to the different intervention groups upon eligibility. Both the research team (i.e. individuals who 
interact directly with the participants and those performing sample analyses) and participants are blinded from the time of randomization and for the duration of the study. The intervention powders will be provided in opaque sachets to assist with blinding. Participants will be instructed not to divulge any information regarding the characteristics of their powders.

\section{Study intervention}

Each sachet will contain 7 grams of the respective intervention powders (equivalent to 6 grams of protein per sachet for the pea protein and whey protein groups); therefore, the number of sachets consumed per day will be based on body weight to achieve a dose of $0.35 \mathrm{~g}$ protein/ $\mathrm{kg}$ body weight/day of soluble pea protein (NUTRALYS $\$$ S85 Plus from Roquette Frères, Lestrem, France) or whey protein (Whey Protein Concentrate 80 Instant Kosher from Osage Food Products, Washington, MO, USA), or an isocaloric amount of maltodextrin (GLUCIDEX 19 from Roquette Frères, Lestrem, France). Participants will be instructed to consume the intervention powders at least twice daily as part of a meal or snack. They are not limited to specific foods or beverages during this study, with the exception of exclusion items (Table 1); however, each participant will receive a variety of optional food and beverage items (Supplementary Table 1) from the study coordinators to assist with incorporating the intervention powders into their diet. An individual not involved with the participants or sample analyses will be responsible for providing the appropriate intervention and quantity of sachets for each participant. Participants will be instructed to return any unused study sachets in order to determine their compliance during the study.

Supplementation of the intervention powders will occur along with a hypocaloric diet (500 kcal/day deficit) which will be uniquely tailored for each participant by a Registered Dietitian (see below). This daily caloric deficit is sufficient to induce a weight loss of approximately 0.5 $\mathrm{kg}$ per week [9]. The caloric intake from the intervention powders and the selection of food and beverage items provided to the participants will be calculated into the hypocaloric diet. The goal for total protein intake will be 1.2-1.4 g protein $/ \mathrm{kg}$ body weight for the protein groups, and $0.8 \mathrm{~g}$ protein $/ \mathrm{kg}$ body weight for the maltodextrin group.

\section{Recruitment and study visits}

Participant Recruitment and Pre-screen: Potential participants (study candidates) will be recruited from Winnipeg, Canada via advertisement through various media. All interested individuals will be briefed on the study procedures over the phone by the study coordinators. If they meet the preliminary eligibility criteria and are still interested in participating, they will be scheduled for an in-person screening visit.

Screening Visit: At the screening visit, study candidates will provide written informed consent. The general consent form details the study schedule, interventions, and assessments (including the collection of biological materials), the time commitment required, the procedure for storing samples, and any potential risks associated with the study. A separate, optional consent form will be provided wherein participants may allow the collection of biological materials (i.e. blood and urine) for analysis of metabolites and gene expression. Candidates will be interviewed for their demographic information as well as medical and surgical histories in order to discern past or current medical problems. Information will be collected regarding concomitant medication and supplement usage (including protein powders or bars), and any relevant information for the inclusion and exclusion criteria. A physical assessment will be conducted including blood pressure, height and weight (for BMI calculation), and bioelectrical impedance (for body fat percentage). Resting energy expenditure will be determined using the Q-NRG Metabolic Monitor (COSMED, Rome, Italy) to assist the Registered Dietitian with planning the individualized calorie restricted diet (Table 2).

A fasting blood sample will be obtained by venipuncture of the antecubital vein for analysis of blood lipid profile (triglycerides, total cholesterol, LDL-cholesterol, and HDL-cholesterol), kidney function (plasma creatinine), liver function (plasma ALT and AST), and glycated hemoglobin. Female participants will also provide a urine sample to test for pregnancy using a urine test strip.

Candidates will be provided with a 3-Day Food Record and various questionnaires for assessing Activity, Quality of Life, Sleep, Appetite, and Eating Habits. Candidates will be instructed to complete the paperwork once they are informed of their eligibility for the study (upon receipt of the bloodwork results) and to return the paperwork at the Pre-Study Visit.

Pre-Study Visit: Eligible participants will have an in-person visit with the study coordinator where they will receive an Escali Glass Body Scale (Escali Corp., MN, USA), Daily Weight Log, Fitbit Charge 3 activity tracker (Fitbit, Inc., CA, USA), and appropriate instructions for their use. Participants will use these items for a minimum of 2-weeks (referred to as the '2-week run-in period') prior to their baseline (week 0) study visit.

Registered Dietitian Visit: The Registered Dietitian will use information gathered from each individual's 3-Day Food Record and resting energy expenditure to develop a personalized nutrition and weight loss plan for each participant. The Registered Dietitian will use the data provided by the Q-NRG Metabolic Monitor for determining resting energy expenditure when the measured output is within $\pm 10 \%$ of the predicted estimation to ensure accuracy is maintained [20-22]. If the measured output is outside of the acceptable accuracy prediction level, resting energy expenditure will be determined manually using the Harris Benedict Equation. Participants will meet with the Registered Dietitian

Table 2. Overview of Study Assessments

\begin{tabular}{|c|c|c|c|c|}
\hline Assessment & $\begin{array}{l}\text { Screening } \\
\text { Visit }\end{array}$ & Baseline Visit & Week 6 Visit & $\begin{array}{c}\text { Week } 12 \\
\text { Visit }\end{array}$ \\
\hline $\begin{array}{l}\text { Physical anthropometrics } \\
\text { (Height, weight, calculated } \\
\text { BMI) }\end{array}$ & $\mathbf{X}$ & & & \\
\hline $\begin{array}{l}\text { Body circumferences (arm, } \\
\text { waist, leg, and calf) and } \\
\text { weight }\end{array}$ & & $\mathbf{X}$ & $\mathbf{X}$ & $\mathbf{X}$ \\
\hline $\begin{array}{l}\text { Bioelectrical impedance } \\
\text { (Body fat \%) }\end{array}$ & $\mathbf{X}$ & $\mathbf{X}$ & $\mathbf{X}$ & $\mathbf{X}$ \\
\hline $\begin{array}{l}\text { Metabolic cart } \\
\text { (Energy expenditure) }\end{array}$ & $\mathbf{X}$ & $\mathbf{X}$ & $\mathbf{X}$ & $\mathbf{X}$ \\
\hline $\begin{array}{l}\text { Fasting blood and urine* } \\
\text { sample }\end{array}$ & $\mathbf{X}$ & $\mathbf{X}$ & $\mathbf{X}$ & $\mathbf{X}$ \\
\hline $\begin{array}{l}\text { DEXA } \\
\text { (Whole body and regional } \\
\text { lean and fat composition) }\end{array}$ & & $\mathbf{x}$ & $\mathbf{X}$ & $\mathbf{x}$ \\
\hline $\begin{array}{l}\text { Physical Performance } \\
\text { (Hand grip strength, gait } \\
\text { test) }\end{array}$ & & $\mathbf{X}$ & $\mathbf{X}$ & $\mathbf{X}$ \\
\hline Blood pressure & $\mathbf{X}$ & $\mathbf{X}$ & $\mathbf{X}$ & $\mathbf{X}$ \\
\hline $\begin{array}{l}\text { Arterial stiffness } \\
\text { (Pulse wave velocity) }\end{array}$ & & $\mathbf{X}$ & $\mathbf{x}$ & $\mathbf{x}$ \\
\hline
\end{tabular}

*Required only from females at screening.

Abbreviations: BMI: body mass index; DXA: dual x-ray absorptiometry. 
Table 3. Blood and urine analysis

\begin{tabular}{|c|c|c|}
\hline Indication & Measured parameter & Biological fluid \\
\hline Adipocyte (dys)function & $\begin{array}{l}\text { - Free fatty acids } \\
\text { - Adipokines (adiponectin, adipsin, } \\
\text { apelin, leptin) }\end{array}$ & \multirow{7}{*}{ Blood } \\
\hline Systemic inflammation & - C-reactive protein & \\
\hline Metabolic function & $\begin{array}{l}\text { - } \text { Insulin* } \\
\text { - Glucose* } \\
\text { - } \text { Adipokines (adiponectin, leptin, } \\
\text { apelin, adipsin) } \\
\text { - } \text { Lipid profile } \\
\text { - Glucagon-like peptide-1 }\end{array}$ & \\
\hline Muscle function & $\begin{array}{ll}\text { - } & \text { Acyl-carnitines } \\
\text { - } & \text { Irsin } \\
\text { - } & \text { Interleukin-15 } \\
\text { - } & \text { Interleukin-32 }\end{array}$ & \\
\hline Hyperglycemia & - Glycated hemoglobin ${ }^{\dagger}$ & \\
\hline Kidney function & $\begin{array}{l}\text { - } \text { Blood urea nitrogen } \\
\text { - }\end{array}$ & \\
\hline Liver function & $\begin{array}{l}\text { - Alanine aminotransferase } \\
\text { - Aspartate aminotransferase }\end{array}$ & \\
\hline Kidney function & $\begin{array}{l}\text { - } \\
\text { - } \\
\text { - Creatininine } \\
\text { - Nitrogen }\end{array}$ & \multirow[t]{2}{*}{ Urine } \\
\hline Pregnancy ${ }^{\|}$ & - Human chorionic gonadotropin & \\
\hline
\end{tabular}

*Used in the calculation of Homeostatic Model Assessment of Insulin Resistance. $\dagger$ Measured at baseline and week 12 visits only.

\$Used in the calculation of estimated Glomerular Filtration Rate. §Used for determining Albumin-to-Creatinine ratio for indication

qMeasured in female participants only.

no more than five days prior to their baseline visit. At this visit, the Registered Dietitian will provide the personalized nutrition counselling for achieving the hypocaloric diet and discuss methods for incorporating the intervention powders into their individualized meal plans.

Baseline, Week 6, and Week 12 Visits: Participants will attend a total of three on-site, in-person intervention study visits: baseline, week 6 , and week 12 . After completing the 2 -week run-in period, participants will arrive fasted (12-hour) to the baseline study visit wherein information on anthropometric characteristics will be collected by the study coordinators using standardized methods. The measurements will include body weight and circumferences of the arm, waist, leg (upper thigh) and calf, and calculation of BMI and waist-to-height ratio. Height will have previously been measured during the Screening Visit using a stadiometer included with the weigh scale (DETECTO, MO, USA). Metabolic assessments will include whole body composition by DEXA using the GE Lunar Prodigy DEXA Scanner (General Electric, Boston, MA, USA) and by bioelectrical impedance using the InBody570 (InBody Co., Ltd., Seoul, Korea), regional body composition by DEXA and visceral fat quantification using CoreScan ${ }^{\mathrm{m} m}$ software (General Electric, Boston, MA, USA), and determination of resting energy expenditure (as described under 'Registered Dietitian Visit'). Vascular health assessments will include blood pressure using the BPTru ${ }^{\text {Tx }}$ BPM200 Blood Pressure Monitor (VSM MedTech Ltd., BC, Canada) and pulse wave velocity using the VP-1000 Vascular Profile Device (Omron Healthcare Inc., IL, USA). Muscle functionality will be assessed by Physical Performance tests, including handgrip measurements with

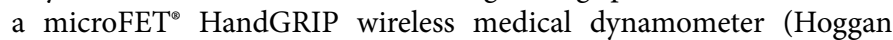
Scientific LLC, UT, USA) and a gait speed test [calculated as the time to walk $4 \mathrm{~m}$ at regular pace $(\mathrm{m} / \mathrm{s})$ [23]] (Table 2).

Fasting blood will be collected via venipuncture of the antecubital vein and a urine sample will be obtained for analysis of various parameters (Table 3). For females, a portion of the urine will be used for a pregnancy test to determine whether it is safe to perform the DEXA scan.
At the end of the baseline and week 6 study visits, participants will receive a 6-week supply of their respective intervention powder sachets to consume daily, a selection of food and beverage items, a Daily Study Food Log, a Daily Weight Log, and 3-Day Food Records and Appetite questionnaires to be completed during Weeks 3, 6, 9, and 12. Additionally, Quality of Life, Sleep, and Eating Habits questionnaires will be distributed at Week 6 to be completed during Week 12 (Figure 1).

\section{Participant compliance}

Participants will be required to record how many sachets they consumed each day in the Daily Study Food Log, as well as at what times these sachets were consumed and what foods or beverages they were consumed with. The study coordinators will be following up with each participant on a bi-weekly schedule to record general well-being, body weight progress and compliance with consumption of the study sachets and a hypocaloric diet. At the Week 6 and Week 12 visits, participants will be required to return any unused study sachets. Returned sachets will be counted against distributed sachets to determine overall compliance. A major protocol deviation for sachet consumption will include participants: 1) having missed consuming more than $40 \%$ of intervention doses (based on $\mathrm{kg}$ body weight) during the 7 days preceding blood and urine collection; and/or 2) having consumed $<85 \%$ of the intervention doses during the 12 -week study.

\section{Statistical analyses}

The primary endpoints (change in muscle mass and function) will be analyzed by the Intention-to-Treat (ITT) principle. The ITT principle includes every participant who is randomized in the study, regardless of noncompliance, protocol deviations, withdrawals, missing outcomes, etc. and is believed to maintain prognostic balance and preserve samples size and thus, statistical power [24]. The ITT analysis is recommended by the Consolidated Standards of Reporting Trials (CONSORT) for improving report quality of randomized clinical trials. In addition to ITT, the data will also be analyzed using Per-Protocol analysis, which uses a subset of the ITT population who completed the study without any major protocol deviations (defined under 'Participant compliance) [24]. Conducting both ITT and Per-Protocol analyses will increase confidence in the study results.

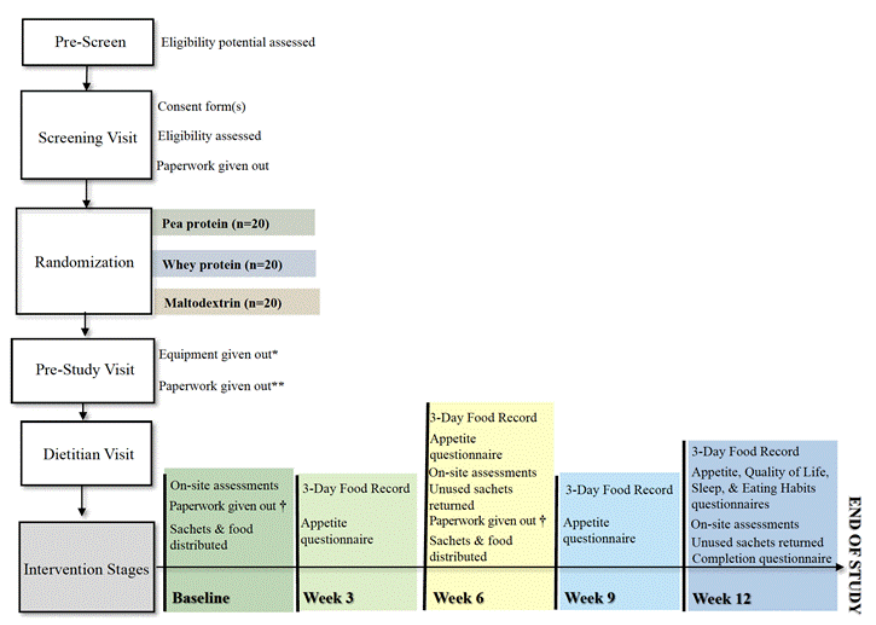

Figure 1. Study overview

*, weigh scale and activity tracker; **, Weight Log, 3-Day Food Record, Questionnaires (Activity, Appetite, Eating Habits, Quality of Life, Sleep); †, 3-Day Food Records, Questionnaires (Appetite, Eating Habits, Quality of Life), Study Food Log, Weight Log 
A mixed methods repeated measures approach (PROC MIXED) will be used to determine the effects of intervention type on body composition (and remaining secondary outcomes) over time, as well as to compare between the intervention groups at Weeks 6 and 12 . Differences from baseline within an intervention group, differences between intervention groups at each timepoint, and effect sizes will be determined by differences of least squares means and adjusted $p$-values (Tukey-Kramer adjustment). Pearson's (or Spearman's) correlation analysis will be used to identify correlations between body composition and other outcomes. The level of statistical significance will be $p<0.05$.

\section{Sample size calculation}

There have been no other studies investigating the effects of pea protein or whey protein on our particular primary outcomes (muscle mass, grip strength, and gait speed) during weight loss in our specific demographic range (i.e. middle-aged, obese individuals) to help guide our calculation for a sufficient sample size. Previous studies have investigated protein supplementation during weight loss in healthy or obese elderly individuals with primary outcomes such as muscle leg strength ( $n=25 /$ group; [25] or thigh muscle volume ( $n=18-27$ ) group; [26], respectively. Therefore, as a pilot study, a sample size of 60 participants ( $n=20 /$ group, and replacement of dropouts) is expected to be sufficient to provide data for a Power Calculation to determine the number of participants needed for a full-scale study.

\section{Ethics}

The protocol was approved by the University of Manitoba Biomedical Research Ethics Board and the St. Boniface Hospital Research Review Committee. The Natural and Non-Prescription Health Products Directorate at Health Canada issued a Notice of Authorization for the study protocol. The study is registered on Clinicaltrials.gov (NCT04123938). The final results of the study will be published in peerreviewed journals.

\section{Discussion}

Obesity is a global epidemic that increases the risk of nearly every chronic disease, including type 2 diabetes, cardiovascular disease, and some cancers [2]. In North America, between $25-42 \%$ of the adult population is classified as obese [3,4]. Lifestyle changes such as calorie restriction and exercise training are important for initiating and maintaining weight loss; however, the loss of whole body weight includes loss of muscle mass, which can increase the risk for reduced strength, impaired daily activities and metabolic regulation, and sarcopenia $[7,8]$. High protein diets have been successful at preserving muscle mass during weight loss [5], but the effectiveness of plant-based protein sources, beyond that of soy protein, has received less attention than their animal counterparts.

There are many different animal- and plant-based protein supplements available to consumers. After a brief internet search, popular animal-based protein sources include whey, casein, milk (a combination of whey and casein), and egg proteins [27,28]. The common stand-alone plant-based protein powders are pea or soy protein, while other plant-based protein powder compositions include combinations of pea, soy, pumpkin seed, watermelon, brown rice, quinoa, sunflower seed, lentil, hemp seed, and/or flax seed proteins [27,28]. Of the various protein sources on the market, whey protein is the most abundant $[27,28]$ and is considered an effective and convenient animal protein source to promote muscle protein synthesis, thereby assisting in the retention of muscle mass while also promoting fat mass loss [29-31]. The positive effect of whey protein on body composition is suggested to be due to its high concentration of branched chain amino acids, particularly leucine, and its high bioavailability and solubility $[26,29,32,33]$. High protein intake (1.1-1.5 g/kg body weight/day or $25-35 \%$ of daily energy intake) provides favourable effects on weight loss and body composition by promoting the loss of fat mass and/or retaining muscle mass [5,34-36]. In obese adults undergoing weight loss programs $(500-600 \mathrm{kcal} /$ day deficits), whey protein supplementation (0.74-1.11 g protein $/ \mathrm{kg}$ body weight/day from supplements alone) was shown to preserve muscle mass by $1.34 \mathrm{~kg}$ compared to controls [37] or increase muscle mass gains compared to the controls ( $+0.4 \mathrm{~kg}$ gain $v s-0.5 \mathrm{~kg}$ loss, respectively) [10]. In addition to these two individual randomized, controlled clinical trials, various meta-analyses have reviewed the effects of whey protein on body composition and/or weight in comparison or in conjunction with other modalities such as resistance training or different protein sources $[11,12,33]$. The combination of resistance exercise with protein supplementation (including whey protein) has been found more effective than resistance exercise alone at preventing muscle mass loss [38]. That said, whey protein has shown favourable effects on body composition (i.e. reduced body fat) and body weight as a stand-alone supplement without the assistance of hypocaloric diets or exercise training [33] or when compared to non-protein carbohydrate control products [12]. However, when compared to other protein sources in the previously mentioned meta-analyses, such as casein (animal-based) and soy (plant-based), whey protein did not perform better [11,12]. Plant-based protein sources are typically considered to be less efficient for stimulating muscle protein synthesis, and thus preserving muscle mass [5] compared to animal-based proteins [39]. However, the metaanalysis findings above suggest that plant-based protein (e.g. soy) may be equivalent to whey protein with respect to changes in body composition during weight loss.

While whey protein is the most popular protein supplement consumed [40,41], its effects on retaining muscle mass have not been compared against a plant-based source other than soy protein, such as pea protein, in humans with obesity undergoing a weight loss diet. This study aims to provide valuable data on the type of protein that can prevent or slow the muscle loss that occurs during a weight reduction program. To the best of our knowledge, this is the first randomized, double-blinded, comparator-controlled study to use dietary pea protein for a long duration in obese men and women. As well, to our knowledge, this is the first study to measure muscle preservation in response to pea protein. Two other studies have investigated pea protein with obese individuals, as determined by a PubMed search of "pea protein and obesity" in July 2020. Geraedts, et al. [17] administered intact pea protein in lean and obese men, but not women, and measured satiety responses and food intake levels for a short duration of 2 hours. Teunissen-Beekman, et al. [42] administered a mixture of protein, which included pea protein, to overweight and obese individuals with high blood pressure. Neither of these studies employed a weight loss regimen or investigated body composition or physical performance (e.g., muscle functionality).

This study will employ three non-invasive testing methods to assess muscle mass and functionality, the primary study outcomes. For the purposes of this manuscript, "muscle mass" refers to total body lean soft tissue (LST). LST mass includes skeletal muscle and other organ tissues [43]. One of the most widely used and gold standard techniques for measuring LST mass, and whole-body composition, at the tissue level is DEXA $[43,44]$. The principle of DEXA is described as the level of attenuation of X-ray beams passing through complex materials, such as bone, adipose, and LST. The dual-energy spectra (high and low energy levels) differentiate between bone and soft tissue materials (adipose and LST), such that the X-ray beams are attenuated less 
with soft tissues (i.e. lower density materials, thus more absorption of photons) compared with bone (i.e. a higher density material, thus less absorption of photons) [43,44]. DEXA is the preferred method for body composition assessments due to its inexpensive scan costs (relative to other techniques), low radiation exposure (approximate equivalent to the radiation dose after being outside for a day at sea level), short scan times (on average 10-20 minutes depending on body size), and ability to measure whole-body and regional compositions [43-45]. Additionally, CoreScan ${ }^{\text {Tw }}$ software can be applied to DEXA scans for quantification of visceral fat in participants [46] thus enabling selective analysis of visceral obesity (a body composition phenotype defined as excessive deposition of abdominal adipose tissue [47]. Various clinical studies have supported the use of DEXA for determining the lean body (muscle) mass during weight loss interventions [48-50]. Reduced muscle mass impairs physical performance by means of diminished muscle strength and function [51]. Hand grip strength is commonly used as a measure to predict total muscle, or overall, strength [52,53]. Hand grip dynamometers measure localized muscle strength generated by the flexor muscles of the hand and forearm and is strongly correlated with muscle strength of other muscle groups, thereby acting as a predictor of overall muscle strength [51,52]. The gait speed test is used to assess the performance of muscle functionality (i.e. mobility) [53] and is often employed in sarcopenia studies [23]. Theoretically, a decline or improvement in muscle functionality should be reflected as a decrease or increase in gait speed, respectively [54]. The three above mentioned assessments (DEXA, hand grip strength, and gait speed) when used in conjunction with each other will provide comprehensive information on the compositional and functional changes in muscle that possibly will occur in our study.

\section{Study strengths}

This study will be the first ever to provide information regarding the effects of pea protein as a functional ingredient for muscle preservation in a dietary weight loss regimen. Searching PubMed for "pea protein and weight loss" or "pea protein and muscle function" did not yield any study with a similar study design or outcomes as the current study. The data from this pilot study may provide the basis to explore a full-scale clinical trial.

Participants will be provided their study results upon completion. We believe providing this information will encourage compliance throughout the study and will provide valuable information to participants regarding their health. The research team understands that this study extends beyond data collection and that for some participants, this study will provide the resources and support they need in order to make life-changing adjustments for their health. Therefore, providing their individual results at the end of the study will provide a sense of empowerment and increase each participant's knowledge of their personal health journey for the 12 weeks they were involved in our study. Additionally, participants will have access to the Registered Dietitian while involved in this study and will be able to keep the fitness tracker and weigh scale provided.

The high-quality design of our study is a strength. The randomized, double-blind, comparator features of this study are considered the gold standard for clinical trials [55]. As well, all phlebotomy services and study assessments will occur in a single site, which will aid in convenience for participants. We will be employing multiple methods for assessing adiposity in this study, as BMI, the defining characteristic, is an imprecise measure of body fat and does not distinguish between lean and fat masses [8]. In addition to BMI, waist circumference and body fat percentage will be used as indicators of adiposity or "obesity", as they reflect visceral and total body adiposity, respectively $[8,56]$.
We will also be evaluating the change in other metabolic health parameters, such as fasting glucose, insulin, insulin sensitivity using HOMA-IR calculations, blood lipids, circulating adipokines and inflammatory markers, etc. and their potential relationships with changes in body composition. High protein diets have been effective for improving metabolic parameters during obesity with and without affecting changes in body weight and/or composition [57,58]. The current study will provide further novel information regarding the efficacies of specific animal and plant protein sources (whey protein and pea protein, respectively) on improving these metabolic biomarkers during weight loss and determine whether any changes in the metabolic biomarkers listed above occur in parallel with changes in body composition.

Participants will also wear activity trackers (Fitbit Charge 3) to monitor 24-hour movement including sleep patterns and activity levels. This information will be beneficial for determining whether sleep patterns or activity levels change during the 12 -week intervention, as changes in sleep or activity can be a confounding factor for interpreting the effects of the dietary intervention. Many studies are documenting the link between sleep patterns (getting an appropriate amount of sleep versus too little or too much and day-to-day variability) and health status, including metabolic regulation [59-61].

In the current study, participants will be asked to record what foods or beverages were used for delivery and consumption of the intervention powders. Additionally, a questionnaire will be employed at the end of the study to ascertain from participants which food approaches were preferred with their intervention powders. Once decoded, this information will assist with the identification of suitable food products and/or food approaches for delivery of pea protein in an effective manner for masking its strong flavour [18] and may provide the opportunity for new product development.

\section{Study challenges and limitations}

One of the challenges of this study is not being able to include a cross-over approach due to the nature of the study design. A cross-over trial would reduce the sample size required for statistical power since each participant would act has his or her own control and would reduce variability issues with confounding factors (e.g. age, sex, environment) [62]. However, in this current weight loss study it would not be feasible for participants to undergo weight cycling (i.e. weight loss induced for intervention, weight re-gained during wash-out period, and then weight loss-induced for next intervention, and so on) in order to obtain a cross-over effect.

Resistance exercise training is also noted as an effective method for preserving muscle mass during weight loss and is considered equally beneficial as diet-induced weight loss [5]. For the purposes of this study, our focus is on weight loss using the approach of dietary calorie restriction. This approach will allow us to investigate the effects of the different protein sources (whey vs pea protein) on muscle preservation independent of exercise training. However, the data from this pilot study may provide an indication that exercise training be included in the design of future full-scale studies.

In the current study design, we investigate each protein source separately (i.e. a whey protein group $v s$ a pea protein group) and do not include a protein mixture group (i.e. $50 \%$ whey protein $+50 \%$ pea protein), even though there is evidence that a mixture of plant and animal protein is more effective than the individual proteins [58]. This information may serve as rationale for including a protein mixture group in future full-scale studies, once more information is learned about the efficacy of pea protein powder for our various study outcomes. 


\section{Summary and significance of the study}

In summary, we expect the data from this study will provide new information on how these different proteins affect the loss of muscle mass that will occur during this weight loss regimen. The results will provide the basis for future full-scale studies investigating pea protein in the context of body composition, muscle function, and other parameters related to obesity and weight loss, as well as include additional design information such as protein mixtures or exercise training. Overall, this research provides an opportunity to enhance our understanding of the effects of plant protein (pea) vs animal protein (whey) in humans with obesity undergoing a weight loss diet.

\section{Author Contributions}

Jaime Clark: Writing- Original Draft Preparation, Writing- Reviewing and Editing.

Carla Taylor: Conceptualization, Funding Acquisition, Methodology, Supervision, Writing- Reviewing and Editing. Laetitia Guérin-Deremaux: Conceptualization.

Catherine Lefranc-Millot: Conceptualization.

Peter Zahradka: Conceptualization, Funding Acquisition, Methodology, Supervision, Writing- Reviewing and Editing.

\section{Funding} Mitacs.

JLC was provided fellowship funding by Roquette Frères and

\section{References}

1. https://www.who.int/news-room/fact-sheets/detail/obesity-and-overweight

2. Hruby A, Hu FB (2015) The epidemiology of obesity: a big picture. Pharmacoeconomics 33: 673-689. [Crossref]

3. https://obesitycanada.ca/understanding-obesity/

4. https://www.cdc.gov/obesity/data/adult.html

5. Cava E, Yeat NC Mittendorfer B (2017) Preserving healthy muscle during weight loss. Adv Nutr 8: 511-519. [Crossref]

6. Conti CR (2018) Obesity and weight loss. Eur Cardiol 13: 93-94. [Crosssref]

7. Devries MC, Phillips SM (2015) Supplemental protein in support of muscle mass and health: advantage whey. J Food Sci 80: A8-A15. [Crossref]

8. Wannamethee SG, Atkins JL (2015) Muscle loss and obesity: the health implications of sarcopenia and sarcopenic obesity. Proc Nutr Soc 74: 405-412. [Crossref]

9. Koliaki C, Spinos T, Spinou M, Brinia ME, Mitsopoulou D, et al. (2018) Defining the optimal dietary approach for safe, effective and sustainable weight loss in overweight and obese adults. Healthcare (Basel) 6: 73. [Crossref]

10. Verreijen AM, Verlaan S, Engberink MF, Swinkels S, de Vogel-van den Bosch J, et al. (2015) A high whey protein-, leucine-, and vitamin D- enriched supplement preserves muscle mass during intentional weight loss in obese older adults: a double-blind randomized controlled trial. Am J Clin Nutr 101: 279-286. [Crossref]

11. Messina M, Lynch H, Dickinson J, Reed KE (2018) No difference between the effects of supplementing with soy protein versus animal protein on gains in muscle mass and strength in response to resistance exercise. Int J Sport Nutr Exerc Metab 28: 674-685. [Crossref]

12. Miller PE, Alexander DD, Perez V (2014) Effects of whey protein and resistance exercise on body composition: a meta-analysis of randomized controlled trials. $J \mathrm{Am}$ Coll Nutr 33: 163-175. [Crossref]

13. https://food-guide.canada.ca/en/healthy-eating-recommendations/make-it-a-habit-toeat-vegetables-fruit-whole-grains-and-protein-foods/eat-protein-foods/

14. Mariotti F, Gardner CD (2019) Dietary protein and amino acids in vegetarian diets - a review. Nutrients 11: 2661. [Crossref]
15. Li H, Prairie N, Udenigwe CC, Adebiyi AP, Tappia PS, et al. (2011) Blood pressure lowering effect of a pea protein hydrolysate in hypertensive rats and humans. $J$ Agric Food Chem 59: 9854-9860. [Crossref]

16. Nielsen LV, Kristensen MD, Klingenberg L, Ritz C, Belza A, et al. (2018) Protein from meat or vegetable sources in meals matched for fiber content has similar effects on subjective appetite sensations and energy intake - a randomized acute cross-over meal test study. Nutrients 10: 96. [Crossref]

17. Geraedts MCP, Troost FJ, Munsters MJ, Stegen JHCH, de Ridder RJ, et al. (2011) Intraduodenal administration of intact pea protein effectively reduces food intake in both lean and obese male subjects. PLoS One 6: e24878. [Crossref]

18. Cosson A, Souchon I, Richard J, Descamps N, Saint-Eve A (2020) Using multiple sensory profiling methods to gain insight into temporal perceptions of pea proteinbased formulated foods. Foods 9: 969.

19. Guillin FM, Gaudichon C, Guérin-Deremaux L, Lefranc-Millot C, Azzout-Marniche D, et al. (2020) Multi-criteria assessment of pea protein quality in rats: a comparison between casein, gluten and pea protein alone or supplemented with methionine. $\mathrm{Br} J$ Nutr 1-25. [Crossref]

20. Almajwal AM, Abulmeaty MMA (2019) New predictive equations for resting energy expenditure in normal to overweight and obese population. Int J Endocrinol 2019: 5727496.

21. Amaro-Gahete FJ, Sanchez-Delgado G, Alcantara JMA, Martinez-Tellez B, MuñozHernandez V, et al. (2019) Congruent validity of resting energy expenditure predictive equations in young adults. Nutrients 11: 223. [Crossref]

22. Marra M, Cioffi I, Sammarco R, Montagnese C, Naccarato M, et al. (2017) Prediction and evaluation of resting energy expenditure in a large group of obese outpatients. Int $J$ Obese (Lond) 41: 697-705. [Crossref]

23. Tessier AJ, Wing SS, Rahme E, Morais JA, Chevalier S (2019) Physical functionderived cut-points for the diagnosis of sarcopenia and dynapenia from the Canadian longitudinal study on aging. J Cachexia Sarcopeni 10: 985-999. [Crossref]

24. Gupta SK (2011) Intention-to-treat principle: a review. Perspect Clin Res 2: 109-112. [Crossref]

25. Mori H, Tokuda Y (2018) Effect of whey protein supplementation after resistance exercise on the muscle mass and physical function of health older women: A randomized controlled trial. Geriatr Gerontol Int 18: 1398-1404. [Crossref]

26. Smith GI, Commean PK, Reeds DN, Klein S, Mittendorfer B (2018) Effect of protein supplementation during diet-induced weight loss on muscle mass and strength: a randomized controlled study. Obesity (Silver Spring) 26: 854-861. [Crossref]

27. https://www.gnc.ca/en_CA/protein/view-all-protein/

28. https://orders.popeyeswinnipeg.ca/search?page=3\&q=protein $\% 2 \mathrm{~A}+$ powder $\% 2 \mathrm{~A} \&-$ type $=$ product

29. Björkman MP, Pilvi TK, Kekkonen RA, Kropelin R, Tilvis RS (2011) Similar effects of leucine rich and regular dairy products on muscle mass and functions of older polymyalgia rheumatica patients: a randomized crossover trial. $J$ Nutr Health Aging 15: 462-467. [Crossref]

30. Hector AJ, Phillips SM (2018) Protein recommendations for weight loss in elite athletes: a focus on body composition and performance. Int J Sport Nutr Exec Metab 28: 170-177. [Crossref]

31. Hector AJ, Marcotte GR, Churchward-Venne TA, Murphy CH, Breen L, et al (2015) Whey protein supplementation preserves postprandial myofibrillar protein synthesis during short-term energy restriction in overweight and obese adults. J Nutr 145: 246252. [Crossref]

32. Naclerio F, Larumbe-Zabala E (2016) Effects of whey protein alone or as part of a multi-ingredient formulation on strength, fat-free mass, or lean body mass in resistancetrained individuals: a meta-analysis. Sports Med 46: 125-137. [Crossref]

33. Wirunsawanya K, Upala S, Jaruvongvanich V, Sanguankeo A (2018) Whey protein supplementation improves body composition and cardiovascular risk factors in overweight and obese patients: a systemic review and meta-analysis. $\mathrm{J} \mathrm{Am} \mathrm{Coll} \mathrm{Nutr}$ 37: 60-70. [Crossref]

34. Clifton PM, Bastiaans K, Keogh JB (2009) High protein diets decrease total and abdominal fat and improve CVD risk profile in overweight and obese men and women with elevated triacylglycerol. Nutr Metab Cardiovas Dis 19: 548-554. [Crossref]

35. Kim JE, O'Connor LE, Sands LP, Slebodnik MB, Campbell WW (2016) Effects of dietary protein intake on body composition changes after weight loss in older adults: a systematic review and meta-analysis. Nutr Rev 74: 210-224. [Crossref] 
Clark JL (2021) A pilot study to examine the effect of pea protein on limiting the loss of muscle mass during weight loss: Study design and rationale

36. Wycherley TP, Moran LJ, Clifton PM, Noakes M, Brinkworth GD (2012) Effects of energy-restricted high-protein, low-fat compared with standard-protein, low-fat diets: a meta-analysis of randomized controlled trials. Am J Clin Nutr 96: 1281-1298. [Crossref]

37. Frestedt JL, Zenk JL, Kuskowski MA, Ward LS, Bastian ED (2008) A whey-protein supplement increases fat loss and spares lean muscle in obese subjects: a randomized human clinical study. Nutr Metab (Lond) 5: 8. [Crossref]

38. Liao CD, Tsauo JY, Wu YT, Cheng CP, 6 Chen HC, et al. (2017) Effects of protein supplementation combined with resistance exercise on body composition and physical function in older adults: a systematic review and meta-analysis. Am J Clin Nutr 106: 1078-1091. [Crossref]

39. Trommelen J, Betz MW, van Loon LJC (2019) The muscle protein synthetic response to meal ingestion following resistance-type exercise. Sports Med 49: 185-197. [Crossref]

40. https://health.clevelandclinic.org/7-tips-choosing-best-protein-powder/

41. Kareb O, Aïder M (2019) Whey and its derivatives for probiotics, prebiotics, synbiotics, and functional foods: a critical review. Probiotics Antimicrob Proteins 11: 348-369. [Crossref]

42. Teunissen-Beekman KFM, Dopheide J, Geleijnse JM, Bakker SJL, Brink EL, et al. (2012) Protein supplementation lowers blood pressure in overweight adults: effect of dietary proteins on blood pressure (PROPRES), a randomized trial. Am J Clin Nutr 95: 966-971.

43. Buckinx F, Landi F, Cesari M, Fielding RA, Visser M, et al. (2018) Pitfalls in measurement of muscle mass: a need for referenced standard. $J$ Chachexia Sarcopeni Muscle 9: 269-278. [Crossref]

44. Bazzocchi A, Ponti F, Albisinni U, Battista G, Guglielmi G (2016) DXA: technical aspects and application. Eur J Radiol 85: 1481-1492. [Crossref]

45. Shepherd J, Ng B, Sommer M, Heymsfield SB (2017) Body composition and DXA. Bone 104: 101-105.

46. https://www.gehealthcare.com/products/bone-and-metabolic-health/corescan

47. Shuster A, Patlas M, Pinthus JH, Mourtzakis M (2012) The clinical importance of visceral adiposity: a critical review of methods for visceral adipose tissue analysis. $\mathrm{Br}$ J Radiol 85: 1-10. [Crossref]

48. Gomez-Arbelaez D, Bellido D, Castro AI, Ordoñez-Mayan L, Carreira J, et al. (2017) Body composition changes after very- low-calorie ketogenic diet in obesity evaluated by 3 standardized methods. J Clin Endocrinol Metab 102: 488-498. [Crossref]

49. Goni L, Riezu-Boj JI, Milagro FI, Corrales FJ, Ortiz L, Cuervo M, et al. (2018) Interaction between an $\mathrm{ADCY} 3$ genetic variant and two weight-lowering diets affecting body fatness and body composition outcomes depending on macronutrient distribution: a randomized trial. Nutrients 10: 789. [Crossref]
50. Moreno B, Crujeiras AB, Bellido D, Sajoux I, Casanueva FF (2016) Obesity treatment by very low-calorie ketogenic diet at two years: reduction in visceral fat and on the burden of disease. Endocrine 54: 681-690. [Crossref]

51. Lindblad A, Dahlin-Ivanoff S, Bosaeus I, Rothenberg E (2015) Body composition and hand grip strength in healthy community-dwelling older adults in Sweden. J Aging Res Clin Practice 4: 154-158

52. Hogrel JY (2015) Grip strength measured by high precision dynamometry in healthy subjects from 5 to 80 years. BMC Musculoskelet Disord 16: 139 .

53. Bohannon RW. Grip strength: an indispensable biomarker for older adults. Clin Interv Aging 14: 1681-1691. [Crossref]

54. Ferre X, Villalba-Mora E, Caballero-Mora MA, Sanchez A, Aguilera W, et al. (2017) Gait speed measurement for elderly patients with risk of frailty. MIS.

55. Misra S (2012) Randomized double blind placebo control studies, the "Gold Standard" in intervention based studies. Indian J Sex Transm Dis AIDS 33: 131-134. [Crossref]

56. De Lorenzo A, Soldati L, Sarlo F, Calvani M, Di Lorenzo N, et al. (2016) New obesity classification criteria as a tool for bariatric surgery indication. World J Gastroenterol 22: 681-703. [Crossref]

57. Te Morenga LA, Levers MT, Williams SM, Brown RC, Mann J (2011) Comparison of high protein and high fiber weight-loss diets in women with risk factors for the metabolic syndrome: a randomized trial. Nutr J 10: 40. [Crossref]

58. Wojcik JL, Devassy JG, Wu Y, Zahradka P, Taylor CG, et al. (2016) Protein source in a high-protein diet modulates reductions in insulin resistance and hepatic steatosis in fa/ fa Zucker rats. Obesity (Silver Spring Md.) 24: 123-131. [Crossref]

59. Cassidy S, Chau JY, Catt M, Bauman A, Trenell MI. Low physical activity, high television viewing and poor sleep duration cluster in overweight and obese adults; a cross-sectional study of 398,984 participants from the UK Biobank. Int J Behav Nutr Phys Act 14: 57. [Crossref]

60. Huang T, Redline S (2019) Cross-sectional and prospective associations of actiographyassessed sleep regularity with metabolic abnormalities: the Multi-Ethnic Study of Atherosclerosis. Diabetes Care 42: 1422-1429. [Crossref]

61. Rayward AT, Duncan MJ, Brown WJ, Plotnikoff RC, Burton NW (2017) A crosssectional cluster analysis of the combined association of physical activity and sleep with sociodemographic and health characteristics in mid-aged and older adults. Maturitas 102: 56-61. [Crossref]

62. Wellek S, Blettner M (2012) On the proper use of the crossover design in clinical trials part 18 of a series on evaluation of scientific publications. Dtsch Arztebl Int 109: 276281. [Crossref]

Copyright: (C2021 Clark JL. This is an open-access article distributed under the terms of the Creative Commons Attribution License, which permits unrestricted use, distribution, and reproduction in any medium, provided the original author and source are credited. 